Int. J. Electrochem. Sci., 15 (2020) 3400 - 3409

\title{
Electro-oxidation of Urea on the Nickel Phosphate-based Nanomaterials
}

\author{
Hongmei Zhang, Yingying Zhang, Min Wang, Yunhui Shen, Benzhi Liu* \\ School of Environmental Science and Engineering, \\ Key Laboratory for Advanced Technology in Environmental Protection of Jiangsu Province, Yanche \\ ng Institute of Technology, Yancheng, China \\ *E-mail: benzhiliu@163.com
}

doi: $10.20964 / 2020.04 .02$

Received: 26 November 2019 / Accepted: 26 January 2020 / Published: 10 March 2020

\begin{abstract}
Nickel phosphate nanomaterials and multi-walled carbon nanotubes (MWCNTs) supported nickel phosphate nanomaterials were prepared by simple precipitate method. The nickel phosphate nanomaterials were tested the electrochemical activity of urea oxidation by cyclic voltammetry in alkaline solution. The nickel phosphate nanomaterials showed high catalytic performance towards the electro-oxidation of urea. Moreover, MWCNTs supported nickel phosphate nanomaterials showed higher catalytic current and lower onset potential due to the large specific surface and high electrical conductivity of MWCNTs.
\end{abstract}

Keywords: Nickel phosphate; Urea; Electro-oxidation; Multi-walled carbon nanotubes

\section{$\underline{\text { FULL TEXT }}$}

(C) 2020 The Authors. Published by ESG (www.electrochemsci.org). This article is an open access article distributed under the terms and conditions of the Creative Commons Attribution license (http://creativecommons.org/licenses/by/4.0/). 